\title{
Cytotoxicity of Fusobacterium ulcerans
}

\author{
BEVERLEY ADRIAANS* and HEMDA GARELICK
}

\begin{abstract}
Department of Medical Microbiology, London School of Hygiene and Tropical Medicine, Keppel Street, London WC1E 7 HT
\end{abstract}

\begin{abstract}
Summary. A new species of Fusobacterium, F. ulcerans, was isolated from 46 tropical ulcers. All the isolates had shown identical soluble cell protein patterns on polyacrylamide gel electrophoresis although there were two morphological types with slightly different biochemical properties. A representative strain of each of the two groups was selected for in- vitro cytotoxicity testing on a range of tissue-culture cell lines. Both strains of $F$. ulcerans induced a marked cytotoxic effect on Vero and Int407 cells. This effect may contribute to the pathogenesis of tropical ulcers.
\end{abstract}

\section{Introduction}

Tropical ulcers are common among young children in the tropics but the disease is not confined to those areas. The lesions start as painful papules which break down over 3-5 days to become large, necrotic, foul smelling ulcers. The rapid progress of ulceration suggests that a toxic factor may be involved in its pathogenesis. The aetiology and pathogenesis of these ulcers was investigated and 120 patients in five tropical areas (Gambia, Zambia, southern India, Fiji and Papua New Guinea) were studied. In all locations the disease followed a similar pattern. Fusobacteria were cultured from swabs taken from 46 of these ulcers and the same organisms could also be identified in the dermis of the ulcers by electronmicroscopy of biopsy samples (Adriaans and Drasar, 1987).

The isolates showed minor biochemical and morphological differences. However, polyacrylamide gel electrophoresis (PAGE) of their soluble cell proteins showed identical patterns (Adriaans and Drasar, 1987). The biochemical characteristics of the fusobacteria and their PAGE patterns differ from any other reported species of Fusobacterium, which suggests that a previously undescribed species may be involved in the pathogenesis of tropical ulcer. The isolates have been characterised and are now referred to as $F$. ulcerans in keeping with their source (Adriaans and Shah, 1988). Since $F$. ulcerans was isolated from patients in several geographical areas, it is suggested that these bacteria may be relevant in the pathogenesis of the disease (Adriaans and Drasar, 1987).

Received 5 Oct. 1988; revised version accepted 11 Jan. 1989. * Present address : Dr B. Adriaans, Department of Dermatology, King's College Hospital, Denmark Hill, London SE5 9RS.
We report our findings on the cytotoxicity of these fusobacteria and discuss their role in the pathogenesis of the disease.

\section{Materials and methods}

\section{Bacterial strains}

A representative strain of each group of Fusobacterium isolated was used in the experiments. The strains used were those deposited with the National Collection of Type Cultures-F. ulcerans NCTC nos. 12111 and 12112. The isolates were grown in $50 \mathrm{ml}$ of Brain Heart Infusion Broth (BHI) (Oxoid) supplemented with haemin, cysteine, and vitamin $\mathrm{K}$ as described by Holdeman et al. (1977). Bacteroides fragilis and Enterobacter cloacae, also isolated from the ulcers, were grown in the same medium.

\section{Preparation of culture supernates}

The anaerobic cultures were incubated for $48 \mathrm{~h}$, at $37^{\circ} \mathrm{C}$, in an anaerobic cabinet with an atmosphere of $\mathrm{H}_{2}$ $15 \%, \mathrm{~N}_{2} 80 \%, \mathrm{CO}_{2} 5 \%$ (Don Whitley Scientific, Shipley, W. Yorks). The $E$. cloacae strains were incubated aerobically for $24 \mathrm{~h}$. Cultures were centrifuged at $3000 \mathrm{~g}$ for $10 \mathrm{~min}$ at room temperature and the supernates were harvested, sterilised by membrane filtration, and tested for cytotoxicity.

\section{Cytotoxicity test}

The cytotoxicity test was based on that of Giugliano et al. (1982). Five cell lines were used: Vero (African green monkey kidney), Chimp liver, Int-407 (human embryonic intestine), CHO-K1 (chinese hamster ovary) and MRC (human diploid lung cells). Cell monolayers were grown in either Medium 199 (Gibco) or Dulbecco's Modified Eagle's Medium (Gibco). Cell monolayers were brought into suspension with trypsin-versene treatment (Giugli- 
ano et al., 1982) and the cells were resuspended in the appropriate test medium, either Medium 199 containing fetal calf serum $5 \%, 20 \mathrm{mM}$ tricene $\left(\mathrm{pH} \mathrm{7.6)}\right.$ and $\mathrm{NaHCO}_{3}$ $0.22 \% \mathrm{w} / \mathrm{v}$, or Dulbecco's Modified Eagle's Medium containing fetal calf serum $10 \%, 20 \mathrm{mM}$ tricene, gentamicin $25 \mu \mathrm{g} / \mathrm{ml}$ and $\mathrm{NaHCO}_{3} 0.22 \% \mathrm{w} / \mathrm{v}$, at a final concentration of $3 \times 10^{5}$ cells $/ \mathrm{ml}$. Cytotoxicity tests were performed in microwell plates (Nunc).

Two-fold dilutions of culture filtrates in test medium were prepared in $100-\mu 1$ volumes to cover a range of dilutions from 1 in 2 to 1 in 256 . Then $100 \mu$ of the cell suspensions were added to each well. Plates were incubated for $24 \mathrm{~h}$ at $37^{\circ} \mathrm{C}$ and all morphological changes were observed at 18 and $24 \mathrm{~h}$. These were graded as: ,$+++ \geqslant 90 \%$ of cells affected;,$++ 70-80 \%$ cells affected,$+ 50-60 \%$ cells affected $;+/-30-40 \%$ cells affected; and - , when $<30 \%$ cells were affected.

Cells were fixed with buffered formaldehyde for $1 \mathrm{~h}$ and stained with $0.001 \%$ phosphate buffered crystal violet. Excess stain was washed from the monolayer and then cell bound stain was eluted with $100 \mu \mathrm{l}$ of acid methanol ( $1 \mathrm{M} \mathrm{HCl} 1 \%$ in methanol) added to each well. The dye concentration was measured by reading the optical density at $540 \mathrm{~nm}$ on a Dynatec plate reader. The bound dye was used as an indicator of cell numbers (Barer et al., $1986 a, b)$.

Each experiment was repeated on at least two occasions. Uninoculated BHI Broth served as a negative control for cytotoxicity and uninoculated growth medium as the negative control for cell survival. Known concentrations of butyrate in uninoculated BHI broth were used to challenge Vero cells.

The butyrate concentration of the culture filtrates was measured by gas liquid chromatography (GLC) (Pye-
Unicam chromatograph, series 204, Philips, Cambridge). The peak area was derived with an integrated computer (PU 4180 computing integrater, Philips). Known concentrations of butyrate were used as standards.

\section{Results}

Filtrates of $F$. ulcerans culture supernates were cytotoxic for Vero and Int-407 cell cultures (table I). Cytotoxicity was demonstrated by morphological changes in the cell monolayers. The affected cells showed long filamentous tendrils when damage was mild and rounding up of cells when the damage was more extensive. The rounded cells often became detached into the medium (figure).

Vero cells were affected most severely; Int-407 cells exhibited similar though less severe changes. The other cell lines were not affected. Cytotoxicity was not observed with the uninoculated BHI broth, nor with culture filtrates of $B$. fragilis or $E$. cloacae. The butyrate concentrations in the culture filtrates are shown in table I. Butyrate added to uninoculated BHI broth in equivalent concentrations produced a similar effect (table II).

\section{Discussion}

The role of infection in tropical ulcers has not been clearly established. Several investigators have suggested that infection as well as malnutrition and trauma may be contributory factors in the patho-

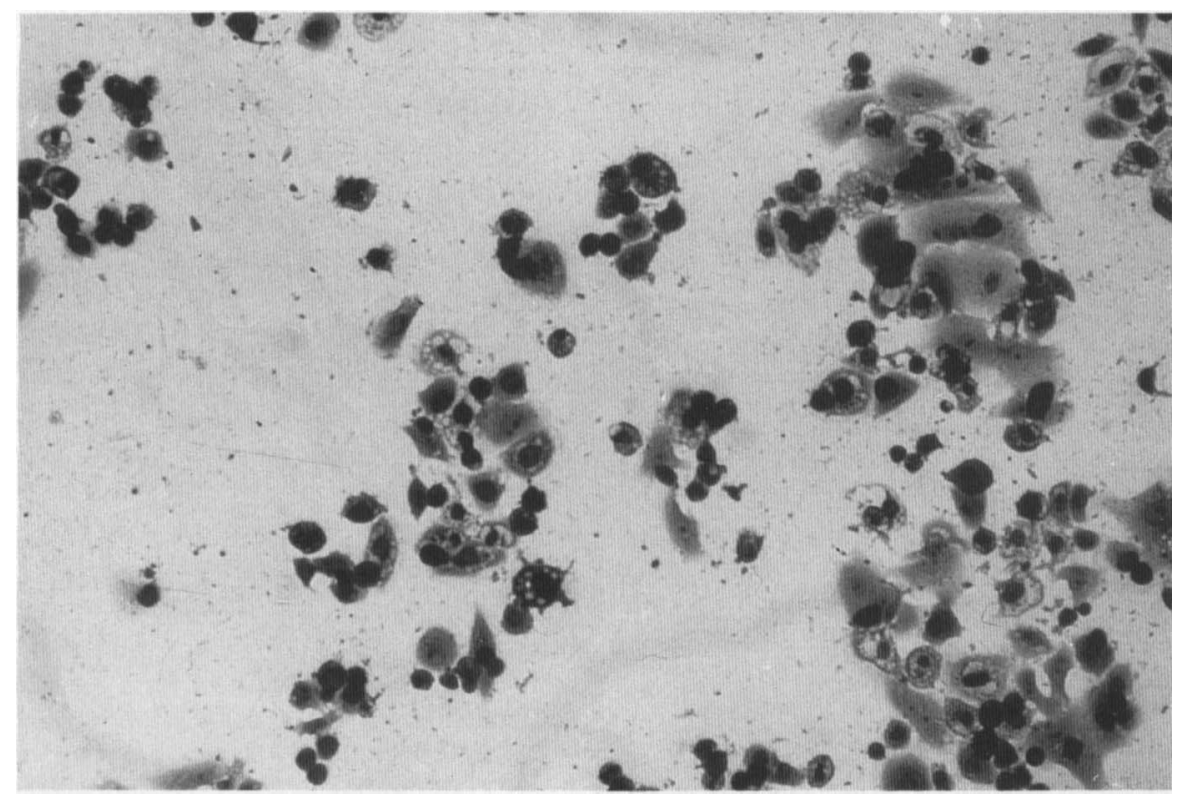

Figure. Vero cells showing cytotoxicity from $F$. ulcerans. (Crystal violet $\times 80$ ). 
Table I. Cytotoxicity of fusobacteria on Vero cells

\begin{tabular}{|c|c|c|c|c|c|c|c|}
\hline \multirow[b]{2}{*}{ Strain } & \multirow{2}{*}{$\begin{array}{l}\text { Butyrate concen- } \\
\text { tration }(M) \text { in } \\
\text { supernate }\end{array}$} & \multicolumn{6}{|c|}{ Cytotoxicity* of culture filtrates at dilutions of } \\
\hline & & 2 & 4 & 8 & 16 & 32 & 64 \\
\hline \multicolumn{8}{|l|}{ F.ulcerans } \\
\hline NCTC 12111 & 0.03 & +++ & +++ & +++ & ++ & + & - \\
\hline \multicolumn{8}{|l|}{ F. ulcerans } \\
\hline NCTC 12112 & 0.03 & +++ & $++t$ & ++ & ++ & + & - \\
\hline B. fragilis & 0 & - & - & - & - & - & - \\
\hline E. cloacae & 0 & - & - & - & - & - & - \\
\hline \multicolumn{8}{|l|}{ Uninoculated } \\
\hline control & 0 & - & - & - & - & - & - \\
\hline
\end{tabular}

* See Materials and methods.

Table II. Effect of butyrate on Vero cell cultures

\begin{tabular}{cc}
\hline Butyrate concentration (M) & Cytotoxicity \\
\hline 0.0025 & + \\
0.005 & ++ \\
0.01 & +++ \\
\hline
\end{tabular}

genesis of the disease (Loewenthal, 1963; Ngu, 1967). Clinical observation of patients with tropical ulcers suggests that infection is a likely factor in the aetiology of this disease because patients often improve when antibiotics are administered early in the disease (B. Adriaans, unpublished observation).

McAdam (1966) was able to transmit tropical ulcers experimentally by inoculating pus from an ulcer of an affected individual to an unaffected area of the same individual. Similar results were obtained by inoculating pus from an affected person into a healthy subject. However, by this method several different organisms from the mixed flora of these ulcers were inoculated and not all of them were necessarily involved in the aetiology of the ulcers. Our previous work has shown that many different species of gram-negative bacteria are present in these tropical ulcers (Adriaans et al., 1987a). The bacteria not only colonise the surface, where they could be regarded as commensals, but they also invade the deeper levels of the ulcer (Adriaans and Drasar, 1987). Fusobacteria have been identified in the dermis by electronmicroscopy of skin biopsies from patients with tropical ulcers.

The rapidity with which the ulcers break down suggests rapid tissue destruction by a toxin or some substance toxic to the connective tissue. Electronmicroscopy showed the presence of abnormal collagen (Adriaans et al., 1987b). In our present study of the effect of several culture filtrates on various cell lines in vitro, Fusobacterium culture filtrates were cytotoxic to Vero cells in culture, whereas filtrates of $B$. fragilis and $E$. cloacae, both isolated from the ulcers, did not produce the same effect. Cytotoxicity in $>50 \%$ of the cells in a well at titres $\geqslant 32$ was produced by both test strains. This was of similar order to the $0.0025 \mathrm{M}$ butyrate concentration which produced the same degree of cytotoxicity when tested separately. Previous work by Grenier and Maynard (1985) showed that butyrate from $F$. nucleatum is cytotoxic to Vero cell lines. Our species of Fusobacterium has not previously been isolated and has only recently been fully characterised (Adriaans and Shah, 1988). The organism is not haemolytic, does not produce extracellular DNAase and does not digest casein, characteristics which should be taken into account in the pathogenesis of destructive disease (Adriaans and Drasar, 1987). The Fusobacterium sp. now known as $F$. ulcerans produces large amounts of butyrate as a metabolic product and these findings are in keeping with the results of Touw et al. (1982) who suggested that toxic concentrations of butyrate may be of aetiological significance in periodontal disease.

We conclude that these fusobacteria may contribute to the development of tropical ulcers. Furthermore, we suggest that their cytotoxicity against Vero and Int- 407 cells may be indicative of similar toxicity to the host tissues which may contribute to the rapid tissue destruction and ulcer formation.

We are grateful to the Wellcome Trust for support. 


\section{REFERENCES}

Adriaans B, Drasar B 1987 The isolation of fusobacteria from tropical ulcers. Journal of Epidemiology and Infection 99: 361-372.

Adriaans B, Hay R, Drasar B, Robinson D 1987a The infectious aetiology of tropical ulcer-a study of the role of anaerobic bacteria. British Journal of Dermatology 116: 31-37.

Adriaans B, Hay R, Lucas S, Robinson D C $1987 b$ The light and electron microscopic features of tropical ulcers. Journal of Clinical Pathology 40: 1231-1234.

Adriaans B, Shah H 1988 Fusobacterium ulcerans sp. nov. from tropical ulcers. International Journal of Systematic Bacteriology 38: 447-448.

Barer M R, Mann G F, Drasar B S 1986a A semi-automated system for the assessment of toxicity to cultured mammalian cells based on detection of changes in staining properties. Developments in Biological Standardization 64: 251-259.

Barer M R, Staley H, Mann G F, Drasar B S $1986 b$ A semiautomated system for detecting changes in the staining properties of cell monolayers applied to the characterization of bacterial enterotoxins. Food and Chemical Toxicology 24: 589-590.
Giugliano L G, Mann G F, Drasar, B S 1982 Response of mammalian cell lines to the toxins of Escherichia coli. Journal of Medical Microbiology 15: 531-539.

Grenier D, Maynard D 1985. Cytotoxic effects of culture supernatants of oral bacteria and various organic acids on Vero cells. Canadian Journal of Microbiology 31 : 302-304.

Holdeman L V, Cato E P, Moore W E C 1977 Anaerobic Laboratory Manual, 4th Ed. Anaerobe Laboratory, Virginia Polytechnic Institute and State University, Blacksburg, VA.p 144.

Loewenthal L J 1963 Tropical phagedenic ulcer-a review. International review of Tropical Medicine 2: 267-291.

McAdam I 1966 Tropical phagedenic ulcers in Uganda: report of an investigation. Journal of the Royal College of Surgeons of Edinburgh 11 : 196-205.

Ngu V A 1967 Tropical ulcers. British Medical Journal 1: 283285.

Touw J J A, van Steenbergen T J, de Graff J 1982 Butyrate: a cytotoxin for Vero cells produced by Bacteroides gingivalis and Bacteroides asaccharolyticus. Antonie van Leeuwenhoek 48: 315-325. 